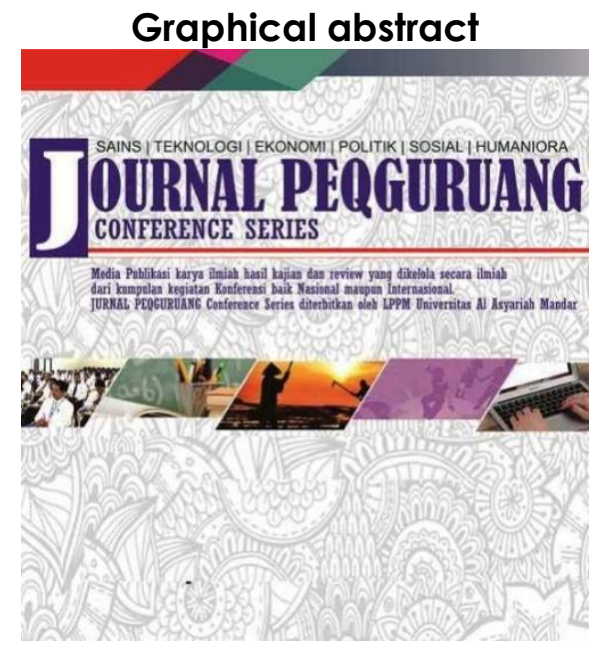

\title{
RESPON PUPUK ORGANIK-AGRODYKE DAN CARA PEMBERIAN BERBEDA TERHADAP PERTUMBUHAN, PRODUKSI BAWANG MERAH (Allium ascalonicum L.)
}

\author{
${ }^{1 *}$ Andi Baso' Harli A Karim , ${ }^{3}$ Iinnaninengseh, Muh \\ Amin \\ Program Studi Agroteknologi, Fakultas Pertanian, \\ Universitas Al Asyariah Mandar
}

Corresponding author

Email. harlipertanian@gmail.com

\begin{abstract}
Shallots have an important meaning for the whole community, both in terms of economic value and nutrition. This research was conducted in Kel Lamungan Batu, Malunda Subdistrict, from July 2019 - September 2019. This study used a Randomized Block Design (RBD) of 2 (two) factors, namely: 3-level agrodyke fertilizer dosage, namely: A1, 3 gr / polybag, A2, 5gr / polybag, A3, $7 \mathrm{gr} /$ polybag. F2 various ways of administration consists of three ways, namely: C1, in Portugal, C2, sprinkled, C3, leaked. conclusions sebgai follows; The interaction between agrodyke fertilizer 3gr / polybag with fertilizer in Portugal (A1C1) has a good effect on the plant height variable $-14 \mathrm{HST}$, as well as the interaction between agrodyke fertilizer 7gr / polybag with fertilizer application by means of a chop (A3C3) has a good effect on the variable plant age14HST, as well as the interaction between agrodyke fertilizer $7 \mathrm{gr} /$ polybag with fertilizer application by means of a chop (A3C3). number of tubers, wet tuber weights and dry tuber weights. The application of Agrodyke 7gr / polybag (A3) fertilizer dose has a good effect on the variable number of tubers, wet tuber weight and dry tuber weight. Fertilizer application by means of leaks (C3) has a good effect on the variable height of plants aged 28 HST, the number of tubers, wet weights and dry tubers weights.
\end{abstract}

Keywords: Production, Productivity, Shallots, Fertilizer-Agrodyke

\begin{abstract}
Abstrak
Bawang merah memiliki arti penting bagi seluruh kalangan masyarakat, baik dari segi nilai ekonomisnya dan gizinya. Penelitian ini dilaksnakan di Kel Lamungan Batu, Kec Malunda, dari bulan Juli 2019 - September 2019. Penelitian ini menggunakan Rancangn Acak-kelompok (RAK) 2 (dua) faktor yaitu: Dosis pemberian pupuk agrodyke 3-taraf yaitu : A1, 3 gr/polybag, A2, 5gr/polybag, A3, 7gr/polybag. F2 berbagai cara pemberian terdiri dari tiga cara yaitu: $\mathrm{C} 1$, di tugal, C2, di taburi, C3, dikocor. simpulan sebgai berikut; Iinterksi antara pupuk agrodyke 3gr/polybag dengan pemberian pupuk dengan cara di tugal (A1C1) berpengaruh baik pada peubah tinggi tanaman umur-14HST, begitupula dengan interkasi antara pupuk agrodyke 7gr/polybag dengan pemberian pupuk dengan cara di kocor (A3C3) berpengaruh baik pada peubah jumlah umbi, bobot umbi basah dan bobot umbi kering. Pemberian dosis pupuk Agrodyke 7gr/polybag (A3) berpengrauh baik pada peubah jumlah umbi, bobot umbi basah dan bobot umbi kering. Pemberian pupuk dengan cara di kocor (C3) berpengruh baik pada peubah tinggi tanaman umur 28 hst, jumlah umbi, bobotumbi basah dan bobot umbi kering.
\end{abstract}

Kata Kunci: Aproduksi, Produktifitas, Bawang Merah, Pupuk-Agrodyke

Article history

DOI: https://dx.doi.org/10.35329/ip.v2i1.679

Received : 07 Januari 2020 | Received in revised form : 11 Februari 2020 | Accepted :09 April 2020 


\section{PENDAHULUAN}

Bawang merah memiliki arti penting bagi seluruh kalangan masyarakat, baik dari segi nilai ekonomisnya dan gizinya. Fungsinyapun sangat bermnfaat bagi kesehatan diantaranya dapatmenurunkan resiko diabetes, pertumbuhan kanker dan resiko gangguang hati. Oleh karena itu peningkatan produksi dan juga mutu harus ditingkatkan (Sumarni dalam Yaya Hasanah 2016; Hikmawati et al. 2020 ).

$\begin{array}{ccc} & \text { Menurut BPS Produksi Nasional bawang } \\ \text { merah Tahun } 2017 \text { 1,47juta ton dan }\end{array}$ produktivitasnya 10,22ton/ha. Namun produktifitas tersebut masih tergolong rendah di banding dengan produktifitas maksimum yang rata-rata dapat mencapai sekitar 15 - 17ton perhektar (Panah Merah, 2019)

Rendahnya produksi dan produktifitas tersebut disebabkan oleh teknologi budidaya yang kurang tepat diantaranya penggunaan pupuk kimiasecara berlebihan dan terus-menerus oleh petani, yang berakibat pada peneurunan sifat kimia, fisik dan biologi yang selanjutnya akan berdampak pada produksi-produktiftas bawang merah itu sendiri.

Untuk mengatasi permasalahan tersebut diatas serta tercapainya produksi dan produktifias yang dinginkan maka perlu adanya terobosan teknologi budidaya yang mampu meningkatkan produksi bawangmerah yaitu melalui pendekatan teknologi pemupukan secara organik, salah satu alternatif yang kami lakukan yaitu menggunakan pupuk organikAgrodyke dengan cara peupukan yang berbeda.

Agrodyke pupuk ramah lingkungan mampu mengembalikan keseimbangan dinamika ekosistem. Pupuk ini mampu meningkatkan produksi yang memberikan nilai tambah yang sangat tinggi terhdap hasil panenan yaitu dengan menghasilkan produk organik, hal ini terbukti dilapangan yang prosesnya akan membuka pori-pori tnah. Terbukanya pori-pori tanah, maka $C, H$, $O$ akan mudah masuk dalam tanah dan proses Transprasi dan Respirsi berjalan normal.

Berdasarkan permasalahan diatas, diperoleh pemikiran untuk melakukan penelitan tentang "Respon Pemberian Dosis Pupuk Agrodyke dan Cara Pemberian yang Berbeda pada Pertumbuhan dan Produksi tanamn Bawang Merah (Allium ascalonicum $L$ )"'

\section{METODELOGI}

Penelitian ini di Kel Lamungan Batu, Kec Malunda, yang berlangsung dari Juli 2019- bulan September 2019.

Metode yang akan kami gunakan adalah RAK dalam bentuk factorial yang nantinya akan dibagi jadi 2 (dua) faktor yaitu:

F1 adalah pemberian pupuk agrodyke dengan 3

taraf:

$$
\begin{aligned}
& \text { A1 }=3 \text { gr/polybag } \\
& \text { A2 }=5 \text { gr/Polybag } \\
& \text { A3 }=7 \text { gr/Polybag }
\end{aligned}
$$

F2 adalah cara pemberian yang berbeda yang terdiri atas 3 carayaitu:

$$
\begin{aligned}
& \mathrm{C} 1=\text { Di Tugal } \\
& \text { C2 }=\text { Di taburi/Piringan } \\
& \text { C3 }=\text { Di kocor }
\end{aligned}
$$

Sehingga terdapat 9 kombinasi perlakuan diulang sebanyak 4-kali, Jumlah kombinasi sebanyak36 dan setip kombinasi penelitian terdiri dari 3/tanaman sehingga jumlah keseluruhan 108 tanaman.

Adapun peubah yang diamati adalah:

1. TT (Tinggi Tanamn), diukur dari pangkal batang-ujung daun tertinggi. dilkukan setiap 2 minggu.

2. JD (Jumlah Daun)/rumpun (helai), jumlah daun dihitung secara keseluruhan. dilkukan 2 minggu sekali.

3. Jumlah Umbi dihitung pada saat panen.

4. Bobot umbibasah (g), dhitung pada saat panen sebelum umbi dikeringkan.

5. Bobot umbikering (g), umbi yang telah dipanen kemudian dijemur selama 1minggu (8 jam/hari).

\section{HASIL DAN PEMBAHASAN}

\section{Tinggi Tanaman Umur 28(HST)}

SK (Sidik Ragam) menunjukan bahwa pemberian pupuk agrodyke dan cara pemberian yang berbeda tidak berpengaruh nyata, tetapi interkasi antara keduanya berpengaruh nyata 
Tabel 1. Rataan Tinggi Tanaman (cm) Bawan Merah Umur 28 HST

\begin{tabular}{cccccc}
\hline \multicolumn{5}{c}{$\begin{array}{c}\text { Bupuk } \\
\text { Agrodyke }\end{array}$} & \multicolumn{4}{c}{ Pupuk } & Rataan $\begin{array}{r}\text { NPBNT } \\
\alpha 0,01\end{array}$ \\
\cline { 2 - 4 } & C1 & C2 & C3 & & \\
\hline A1 & 32.33 & 33.75 & 37.75 & 34.61 & 5.10 \\
A2 & 29.75 & 30.33 & 40.58 & 33.55 & \\
A3 & 32.75 & 30.16 & 42.42 & 35.11 & \\
\hline Rataan & $31.61^{\mathrm{a}}$ & $31.41^{\mathrm{a}}$ & $40.25^{\mathrm{b}}$ & \\
\hline
\end{tabular}

UJBNT taraf 0,01 tabel 1 diatas menunjukkan menunjukan pemberian pupuk agrodyke 3gr/polybag berinteraksi dengan pemberian pupuk dengan cara dikocor. terlhat bahwa perlakuan ini memiliki nilai rata-rata tertinggi bila dibandingkan dengan perlakuan lain, hal tersebut diduga karena UH N-P-K yang terkandung dalam tanah melalui peran pupuk ini sangat dibutuhkan tanaman bawang merah dalam hal meningktkan pertumbuhan dan produksi tanaman tersebut dan juga pemberian pupuk ini juga mampu membantu membka pori-pori pada tanah sehingga $C, H$, $O$ memudakan masuk kedalam-tanah dan proses Transprasi dan Resprasiberjalan normal, sehingga memberikan efek "penghalauan"pada berbagai berbagai organisme hama/penyakit tanaman serta mampu menetralsir $\mathrm{PH}$-tanah. Hal ini sesuai denganpendapat Sukanto (1991) dalam Maulidil Fajri (2014) tanaman kekurangan UH (hara) akan terganggu metabolisnya.

\section{Jumlah Daun Umur 28(HST)}

SK (Sidik Ragam) menunjukan bahwa tidak adanya perlakuan maupun interkasi pemberian pupuk yang berpngaruh nyata

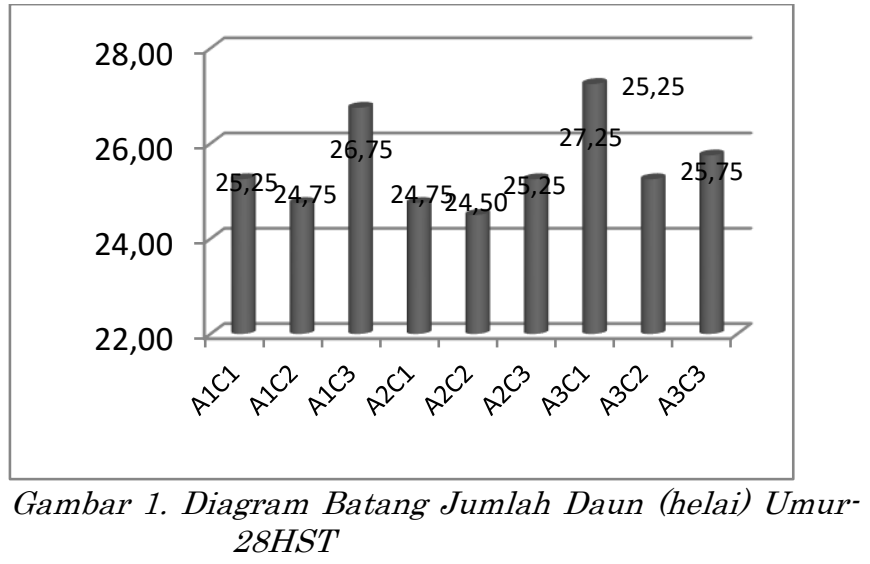

Diagram diatas (gambar 1 ) menunjukan bahwa menunjukkan tidak adanya perlakuan maupun interaksi perlakuan yang berbedanyata, namun bukan berarti tidak ada perlakuan yang baik. Pada diagram batang menunjukan bahwa pemberian pupuk agrodyke 7 gr/polybag dengan cara piringan (A3C2) memiliki ratarata nilaitertinggi terhadap jumlah daun umur 28-HST pemberian pupuk agrodyke 7 gr/polybag dengan cara di tugal (A3C1) memiliki rata-rata nilai tertinggi yaitu 27.25helai. Hal tersebut diduga karena jumlah dan ukuran daun dipengaruhi oleh gentipe tiap tanaman dan kondisi lingkungan disekitar tanaman, Menurut Sunarjono (1989) dalam Muhammad Hidayatullah (2005) selain faktor lingkungan (abiotik) faktor gen tanaman juga sangat berpengaruh pertumbuhan dan perkembangan tanamn.

\section{Jumlah Umbi}

SK (sidik ragam) menunjukan pemberian pupuk agrodyke dengan cara pemberian yang berbeda berpengaruh nyata, begitupun interkasi antara keduanya juga berpengaruh nyata.

Tabel 2. Rataan Jumlah Umbi Bawang Merah

\begin{tabular}{cccccc}
\hline & \multicolumn{3}{c}{ Berbagai Cara Pemberian } & & \\
Pupuk & \multicolumn{3}{c}{ Pupuk } & Rataan & $\begin{array}{r}\text { NPBNT } \\
\alpha 0,01\end{array}$ \\
\cline { 2 - 4 } & $\mathrm{C} 1$ & $\mathrm{C} 2$ & $\mathrm{C} 3$ & & \\
\hline A1 & $4.75^{\mathrm{ax}}$ & $6.75^{\mathrm{ax}}$ & $6.25^{\mathrm{ax}}$ & $5.91^{\mathrm{a}}$ & 1.14 \\
A2 & $6.25^{\mathrm{ax}}$ & $7.00^{\mathrm{ax}}$ & $8.25^{\mathrm{by}}$ & $7.16^{\mathrm{ab}}$ & \\
A3 & $7.25^{\mathrm{bx}}$ & $7.50^{\mathrm{ax}}$ & $10.00^{\mathrm{cy}}$ & $8.25^{\mathrm{b}}$ & \\
\hline Rataan & $6.08^{\mathrm{a}}$ & $7.08^{\mathrm{a}}$ & $8.16^{\mathrm{b}}$ & & \\
\hline
\end{tabular}


UJBNT 0,01 diatas adalah Pemberian pupuk agrodyke 7gr/polybag (A3) dan pemberian dengan caradikocor (C3) berpengaruh baik, hal ini diduga bahwa takaran yang diberikan sudah sesuai dengan pertumbuhan dan perkembangan tanaman bawang merah. takaran pupuk dalam pemupukan haruslah tepat, artinya tidak terlalu sedikit ataupun terlalu banyak yang dapat menyebabkan pemborosan atau dapat merusak akar tanaman. Hal ini sesuai dengan pendapat Setiadi (2008) dalam Maulidil Fajri (2014) pertumbuhan produksi tanaman dipengaruhi oleh faktor tanah/iklim dan tanaman itu sendiri yang semuanya saling berinteraksi.

\section{Bobot Umbi Basah(g)}

SK (sidik ragam) menunjukan pemberian pupuk agrodyke dengan cara pemberian yang berbeda berpengaruh nyata, begitupun interkasi antara keduanya juga berpengaruh nyata.

Tabel 3. Rataan Bobot Umbi Basah (g)

\begin{tabular}{|c|c|c|c|c|c|}
\hline \multirow{2}{*}{$\begin{array}{l}\text { Pupuk } \\
\text { Agrodyke }\end{array}$} & \multicolumn{3}{|c|}{$\begin{array}{c}\text { Berbagai Cara Pemberian } \\
\text { Pupuk }\end{array}$} & \multirow{2}{*}{ Rataan } & \multirow{2}{*}{$\begin{array}{r}\text { NPBNT } \\
\alpha 0,01\end{array}$} \\
\hline & $\mathrm{C} 1$ & $\mathrm{C} 2$ & $\mathrm{C} 3$ & & \\
\hline A1 & $65.33^{a x}$ & $67.50^{\mathrm{ax}}$ & $67.16^{\mathrm{ax}}$ & $66.66^{a}$ & 7.30 \\
\hline $\mathrm{A} 2$ & $74.00^{\mathrm{bx}}$ & $81.50^{\mathrm{bx}}$ & $86.83^{b x}$ & $80.77^{b}$ & \\
\hline A3 & $91.08^{\mathrm{cx}}$ & $89.08^{c x}$ & $108.58^{\text {by }}$ & $96.24^{c}$ & \\
\hline Rataan & $76.80^{\mathrm{a}}$ & $79.36^{a}$ & $87.52^{b}$ & & \\
\hline
\end{tabular}

dari UJBNT diatas memperlihatkan bahwa pemberian pupuk agrodyke 7gr/polybag (A3) dan pemberian dengan caradikocor (C3) membrikan pengaruh baik, serta interksi antara pupuk agrodyke 30gr/polybag dengan pemberian dengan cara dikocor (A3C3) juga memberkan pengruh baik. Hal ini diduga karena kalium yang tersedia didalam tanah melalui pupuk agrodyke sudah mencukupi untuk pses umbi dan meningkatkan hasil berangkasan kering umbi tanaman bawang merah (Sutedjo dan Kartasapoetra dalam Muhammad Hidayatullah. 2005).
Bobot Umbi Kering (g)

SK (sidik ragam) menunjukan pemberian pupuk agrodyke dengan cara pemberian yang berbeda berpengaruh nyata, begitupun interkasi antara keduanya juga berpengaruh nyata.

Tabel 4. Rataan Bobot Umbi Kering(g)

\begin{tabular}{cccccc}
\hline \multirow{5}{*}{$\begin{array}{c}\text { Pupuk } \\
\text { Agrodyke }\end{array}$} & \multicolumn{4}{c}{ Berbagai Cara Pemberian } \\
Pupuk & Rataan & $\begin{array}{r}\text { NPBNT } \\
\alpha 0,01\end{array}$ \\
\cline { 2 - 4 } & $\mathrm{C} 1$ & $\mathrm{C} 2$ & $\mathrm{C} 3$ & & \\
\hline A1 & $42.42^{\mathrm{ax}}$ & $49.66^{\mathrm{ax}}$ & $55.33^{\mathrm{ax}}$ & $49.13^{\mathrm{a}}$ & 3.95 \\
A2 & $58.42^{\mathrm{bx}}$ & $56.92^{\mathrm{bx}}$ & $68.66^{\mathrm{bx}}$ & $61.33^{\mathrm{b}}$ & \\
A3 & $78.75^{\mathrm{cx}}$ & $79.16^{\mathrm{cx}}$ & $87.75^{\mathrm{cy}}$ & $81.88^{\mathrm{c}}$ & \\
\hline $\begin{array}{c}\text { Rata- } \\
\text { Rata }\end{array}$ & $59.86^{\mathrm{a}}$ & $61.91^{\mathrm{a}}$ & $70.58^{\mathrm{b}}$ & & \\
\hline
\end{tabular}

Dari hasil UJBNT diatas meunjukan bahwa Pada bobot kering bawang merah pupuk agrodyke 7gr/polybag (A3) dan pemberian dengan caradikocor (C3) berpengruh, serta interksi antara pupuk agrodyke30gr/polybag $\mathrm{x}$ pemberian dengan cara dikocor (A3C3) juga membrikan pengaruh baik. Hal ini di duga karena pengunan pupuk yang tepat/seimbang akan membantu tanaman tumbuh/berkembang dengan baik dalam hal ini penamabahan bobot kering tanaman.

\section{KESIMPULAN}

Dari hasil penelitian yang dilakukan dapat disimpulkan sebagai berikut :

1. interaksi pupuk agrodyke $3 \mathrm{gr} /$ polybag $\mathrm{x}$ cara di tugal (A1C1) berpengaruh baik pada peubah tinggitanaman umur-14HST, begitupula dengan interksi pupuk agrodyke 7 gr/polybag $\mathrm{x}$ cara dikocor (A3C3) berpengruh baik pada peubah jumlah umbi, bobotumbi basah dan bobot umbi kering.

2. Pemberian pupuk Agrodyke 7gr/polybag (A3) berpengruh baik pada peubah jumlah umbi, bobott umbi basah dan bobot umbi kering.

3. Pemberian pupuk dengan cara di kocor (C3) berpengruh baik pada peubah tinggi tanaman umur-28hst, jumlah umbi, bobott umbi basah dan bobotumbi kering. 
Saran

Berdasarkan hasil penelitian maka kami menyarankan untuk menggunakan Pupuk Agrodyke $7 \mathrm{gr} /$ polybag atau 3gr/polybag, begitupun juga pemberian pupuk dengan cara dikocor untuk mendapatkan hasil pertumbuhan dan hasil yang lebih baik.

\section{DAFTAR PUSTAKA}

Adi Prayitno. 2015. Respon Pemberian Kapur Dolomit dan Pupuk Organik Granule Moderen Terhadap Pertumbuhan dan Hasil Bawang Merah (Allium ascalonicum L.) pada Tanah Berpasir. Palangkaraya: Universitas Muhammadiyah.

Badan Pusat Statistik. 2017. Produksi Bawang Merah.

Badan Pusat Statistik Kabupaten Mamuju. 2015. Produksi Bawang Merah.

Dahlia Duta U. 2018. Distributor Pupuk Agrodyke

Gardner, F.P, R. Brent Pearce dan Roger L. Mitchell. 1991. Fisiologi Tanaman Budidaya. Universitas Indonesia Press. Jakarta.

Hikmahwati, H., Auliah, M. R., Ramlah, R., \& Fitrianti, F. (2020). Identifikasi Cendawan Penyebab Penyakit Moler Pada Tanaman Bawang Merah (Allium

\begin{tabular}{llr} 
Ascolonicum L.) & Di & \multicolumn{2}{c}{ Kabupaten } \\
Enrekang. AGROVITAL: & Jurnal IImu \\
Pertanian, 5(2), 83-86. & & \\
2009. & &
\end{tabular}

Irianto, K. 2009. Sukses Agrobisnis. Jakarta: Sarana Ilmu Pustaka

Lingga, P., dan Marsono. 2008. Petunjuk Penggunaan Pupuk. Penebar Swadaya. Jakarta.

Maulidil Fajri. 2014. Pengaruh Dosis Pupuk Kandang dan Kalium Terhadap Pertumbuhan dan Hasil Tanaman Bawang Merah (Allium cepa L. kelompok Agregatum). Aceh Barat: Universitas Teuku Umar.

Muhammad Hidayatullah. 2005. Respon Dua Varietas Bawang Merah (Allium ascalonicum L) Terhadap Imbangan Pemberian Pupuk Organik Kascing dan Anorganik. Jember: Universitas Muhammadiyah

Panah Merah. 2019 Petani Bawang Merah di Aceh Berhasil Menghasilkan Panen Berlimpah

Pioneer. 2016. Berbagai Cara Pemupukan Tanaman Budidaya.

Sutedjo, MM dan Kartasapoetra S. 2005. Tumbuhan dan Organ-organ Pertumbuhannya. Bina Aksara. Jakarta.

Sando Franciskus Sinaga, Toga Simanungkalit, Yaya Hasanah Yaya. 2016. Respons Pertumbuhan Bawang Merah (Allium ascalonicum L.) Terhadap Pemberian Kompos Sampah Kota dan Pupuk K. Medan: Fakultas Pertanian USU. 